\title{
Examining Emergency Remote Teaching Using the Community of Inquiry Framework: \\ Lecturer Experiences in a Kenyan University
}

\author{
Jane Adhiambo Chiroma, Pan Africa Christian University, Kenya \\ (iD) https://orcid.org/0000-0002-8995-8308 \\ Lawrence Meda, Zayed University, Dubai, UAE \\ Zayd Waghid, Cape Peninsula University of Technology, South Africa
}

\begin{abstract}
The COVID-19 global pandemic has forced many universities worldwide to switch from face-toface classes to emergency remote teaching (ERT) to allow students to continue learning. Using the community of inquiry framework, this study aimed to examine a group of lecturers' experiences of ERT at a university in Kenya. The study was conducted using a qualitative case study design within an interpretive paradigm. Ten lecturers were purposively selected to participate in semi-structured interviews. The findings suggest that these lecturers had established teaching presence, social presence, and cognitive presence to enhance students' learning experiences during the time they engaged in ERT. The community of inquiry was found to be a useful framework by the researchers for lecturers to use in order to rethink, organize, and guide ERT at the university, which was the site of the study. This study has practical implications for course designers, researchers, and students at universities and other educational institutions concerning curriculum re-design using a $\mathrm{CoI}$ as a framework.
\end{abstract}

\section{KEYWORDS}

Cognitive Presence, Community of Inquiry, COVID-19, Emergency Remote Teaching, Lecturers' Experiences, Online Learning, Social Presence, Teaching Presences

\section{INTRODUCTION}

The COVID-19 global pandemic has significantly impacted education, forcing many institutions of learning to make an abrupt shift from conventional face-to-face classes to Emergency Remote Teaching (ERT). It has forced academics to barge into ERT as an approach to mitigating the impact of the current pandemic on teaching and learning. UNESCO (2020) reports COVID-19 to have negatively affected the learning experiences of undergraduate students in institutions of higher learning across the globe. Since most residential universities engage in face-to-face teaching, a sudden switch to ERT could significantly affect the learning of students at such universities. Ontong and Waghid (2020) see the lack of time on the part of lecturers to prepare for online classes as a significant constraining factor on higher education students' capacities to learn effectively. 
This is the case in Africa, including in Kenya, the context of this present study. The Kenyan Ministry of Education (2020) recently expressed concern over the COVID-19 pandemic's disruption of learning for "over 18 million Kenyan learners and trainees which is a threat to the attainment of Sustainable Development Goal number 4 on access to quality, equitable and inclusive education"(p.v). As a preventative measure to reduce the spread of the pandemic, the Government of the Republic of Kenya ordered all educational institutions to be closed indefinitely from March 2020 (Ministry of Education, 2020). However, Online learning is not new to the Kenyan context as some universities and colleges in the country had implemented this model before the pandemic (Paschal \& Mkulu, 2020). Some universities had introduced e-learning before subscribing to the country's Vision 2030 of digital literacy (Tarus \& Gichoya, 2015; Huho, 2020). However, although these universities were already integrating online learning, institutions throughout the country were significantly affected during the time of COVID-19, primarily because some students did not at the time have sufficient resources for ERT (Bozkurt et al., 2020; Ngwacho, 2020).

The inception of ERT in Kenya, as in many other African countries, has been credited by some as a turning point for digital transformation and an opportunity to embrace and consolidate the use of Information and Communication Technology (ICT) in higher education institutions that have often been criticized for their lamentable slow pace (Bozkurt et al. 2020; Tam \& El-Azar 2020; Ontong \& Waghid, 2020). ERT has certainly opened up opportunities not only for curriculum content developers but also for the establishment of higher educational institutions in remote areas where learners can be taught online (Huho, 2020). However, these affordances also present universities (particularly in Kenya as a developing country) with distinct curriculum implementation challenges. The extent to which university lecturers are managing to create opportunities for their students to interact with each other and with lecturers online, construct meaning through sustained communication, and facilitate social and cognitive presences, is yet to be explored fully within the context of ERT in Kenya. Three elements, social, cognitive, and teaching presences, together constitute the cornerstone of Garrison, Anderson, and Archer's (2000) Community of Inquiry (CoI) theoretical framework for creating meaningful and collaborative online learning. These authors, and those who subscribe to this theory, consider these to be essential for establishing an online community. Stenbom, Jansson, and Hulkko (2016) see an effective online class as one that enables students to interact with all three presences to achieve meaningful and collaborative learning in a distance education context.

Thus, the purpose of this present study was to use the CoI framework to examine the experiences of ERT of a sampled group of lecturers at a university in Kenya. The study was guided by one critical question: What are lecturers' experiences of ERT as examined through the lens of the CoI framework? The paper is structured in five sections, which include this section as the introduction to the study. The second section reviews existing literature that focuses on conceptualizing ERT and how the concept can be used effectively to deliver an online curriculum, and how it is experienced by the participating higher education lecturers. A discussion of the theoretical framework guiding this study follows thereafter. The research design and methodology are presented in the third section. The fourth section reports on the findings and discusses the results. The final section presents the conclusion, the implications of this study for ERT and higher education, the study's limitations, and suggests further avenues of research.

\section{Emergency Remote Teaching in Higher Education}

Emergency remote teaching is pedagogical, and a curricular response to teaching in crises. Following the COVID - 19 crisis, higher education across the globe encountered a changing pedagogical terrain, where instructors absorbed students in online learning spaces with alternative technological approaches and academic requirements (White, Tiwari, Yan \& Williams, 2020). ERT as envisioned in this paper is connected to a social constructivist view of education, where students "actively construct their own knowledge" (Woolfolk, 2014:387) and that learning is socially constructed in that both students and instructors participate actively in equal measure in the process of teaching and learning (Woolfolk, 
2014). This kind of education triggers a sense of joint communicative responsibility and learning considered a communal-based inquiry. This way of thinking about education is significant because efforts are made by both the instructor and the student to create a community of learning where the social connection could be lost due to the changing educational landscape in which 'social distancing' may alienate students' learning environment.

Furthermore, it is important to note that ERT and online learning are not synonymous terms. Bozkurt and Sharma (2020) explain that, although the terms are sometimes used interchangeably, they mean two different things. To fully understand ERT, a key construct in this study, it is essential to differentiate it from online learning. The planning process is a significant feature differentiating these two remote learning modes. Online learning is carefully planned well in advance in terms of course design, selection and organization of learning materials, curriculum implementation, and assessment strategies (Anderson, 2011), while ERT often happens, or is resorted to, in response to an unforeseen crisis such as COVID-19. Instructors do not have adequate time to plan for online instruction (Zhang, Wang, Yang \& Wang, 2020), in particular for interactive online activities. In online learning or e-Learning, thoroughly planned student interaction and engagement are the cornerstones (Gillett-Swan, 2017).

ERT is conceptualized as

... not usually planned and involves a sudden shift from traditional teaching into a remote one given emergency situations like the outbreak of Coronavirus in different countries. This is a different situation compared to e-Learning in normal circumstances. After an emergency state, everything is supposed to go back to normalcy. Moreover, educators have to work in a highly stressful situation while having no knowledge of the end of the crisis (Affouneh, Salha \& Khlaif, 2020, p. 1)

This view of ERT could describe the current crisis in many institutions of higher learning, where academics have replaced face-to-face classes with temporary online learning strategies until the global pandemic of COVID-19 will have passed. It is assumed by several higher education analysts and lecturers that, universities that were pre-dominantly teaching using face-to-face, will revert to their former methods at the end of the pandemic. Rahiem (2020) subscribes to this assumption, seeing the ERT mode of online teaching as an interim one, having to be resorted to until the crisis or pandemic is over, and institutions revert to their face-to-face or hybrid classes. Hodges et al. (2020) make a clear distinction between the two types of remote learning, arguing that online learning should not be mistaken for ERT which is happening in most higher education institutions today.

Nyamboga and Ali (2020) found that, despite the challenges experienced by students at one Kenyan university, a significant positive relationship between ERT and students' academic achievement has developed. In this context, some interesting innovations and creative ways of teaching and learning in response to, rather than despite, the pandemic crisis have been reported in universities in Kenya. Huho (2020) reports an innovation at one university where students in collaboration with their lecturers, developed ventilators and COVID 19 test kits. This kind of initiative has been an indicator of the level of technological development capacity available in the country (Huho, 2020, p. 484). As a result of ERT, self-directed learning has become the new norm in Kenyan universities where students are being provided opportunities to learn independently and employ inquiry-based learning strategies (Selvam, 2020). Bozkurt and Sharma (2020) argue that some ERT recently designed and used pedagogical strategies have allowed students to explore content and implement self-directed learning. Students have had to learn different technologies, interact with others, and adapt to the new remote teaching and learning style to achieve their educational goals (Whittle, Tiwari, Yan \& Williams, 2020).

From these studies, we argue that, for effective learning to take place in ERT, there is a need for creating a conducive learning environment that allows such creative and collaborative interactions to take place. Ontong and Waghid (2020) argue that place and space are some of the useful tools to consider in an ERT situation. Similarly, Waghid (2016) postulates that effective remote learning often occurs when students do not feel intimidated by the immediate physical presence of their fellow students and lecturers. 


\section{Community of Inquiry Framework}

Garrison et al's (2000) CoI was used as a theoretical framework for this study. The CoI framework accepts that critical learning requires establishing a community (Swan, Garrison, and Richardson, 2009 , p. 4). As an online learning model, the three interdependent elements of the framework, namely the cognitive, social, and teaching presences, are vital constituents for the pursuit of critical inquiry in educational environments (Swan et al., 2009, p. 5; Waghid, 2016). The theory is built upon a constructivist view of learning and on John Dewey's idea of practical inquiry within a particular community (Fiock, 2020). The three interconnected components of the CoI framework used to support online learning modes are shown in Figure 1.

\section{Social presence}

\section{Cognitive presence}

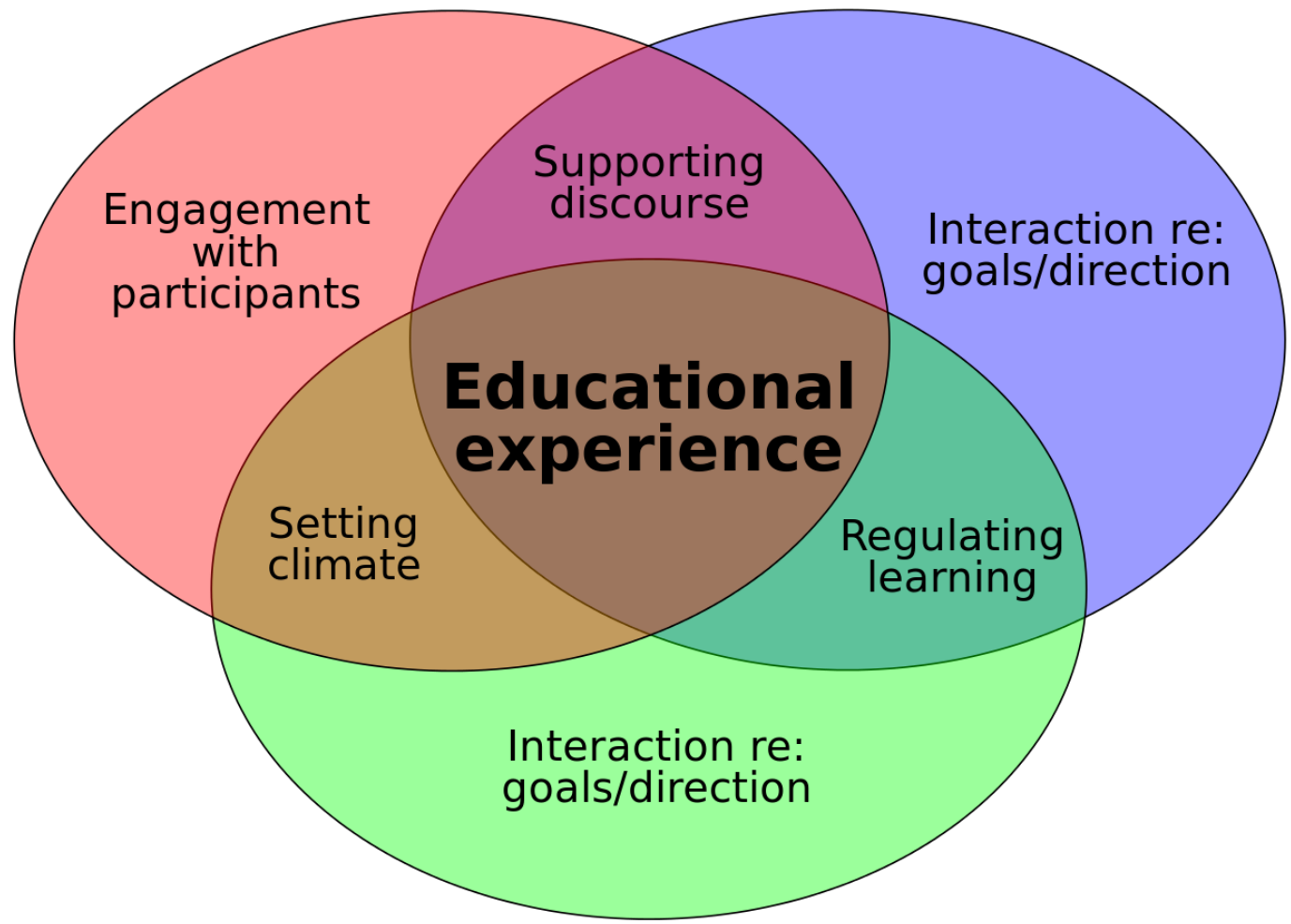

\section{Teaching presence}

\section{Social Presence}

Garrison and Anderson (2007) describe the social presence in the CoI as consisting of open communication, group cohesion, and affective expression. Students communicate online with their fellow students and instructors express their feelings and engage in collaborative tasks to achieve a common educational goal (Garrison et al., 2001). In other words, social presence enables students to project themselves socially and emotionally through interaction and collaboration in online learning. 


\section{Teaching Presence}

Teaching presence consists of three fundamental stages, design and organization, facilitating discourse, and direct instruction (Anderson, Rourke, Garrison, \& Archer, 2001). Design and organization happen before the start of the course where the instructor develops course materials and organizes them in a way that makes it easy for students to navigate around them (Stenbom et al., 2016; Fiock 2020). Facilitating discourse involves the instructor guiding and facilitating students' learning (Garrison \& Anderson, 2007). Students will be given tasks to complete and the instructor makes sure they receive all the necessary support to achieve the learning objectives. According to Anderson et al. (2011), direct instruction involves a teacher providing feedback to students on their work. Teaching presence is fundamental to students' cognitive and social learning. It provides students with guidelines and outcomes required for the learning process. When students have a learning direction, the possibility of student satisfaction and perceived learning becomes prominent (Anderson, et al., 2001). We argue that ERT as a crisis mode of teaching should reflect elements of teaching presence, however, the time put in would vary from the normal online teaching in order to respond to the rapid adaptation to a crisis situation.

\section{Cognitive Presence}

Cognitive presence involves students' use of critical thinking skills to construct meaning and understanding through a deep and sustained reflection (Anderson et al., 2011). According to Garrison et al. (2001), cognitive presence occurs in four stages: the triggering event, exploration, integration, and resolution. A triggering event occurs when a student identifies and conceptualizes a problem or an issue that s/he feels needs to be investigated (Stenbom, Jansson \& Hulkko, 2016). When a student begins to explore the problem or an issue that has been identified, this process is called exploration (Garrison et al., 2001). Stenbom et al. (2016) argue that exploration can occur in many ways, including brainstorming ideas and critically reviewing information. Integration "consists of combining thoughts to make them operational" (Stenbom et al., 2016, p. 39). In other words, integration involves the process where students develop ideas and meanings that they already explored to a higher level of learning. The last stage, resolution, is the process, in the course of which a problem or issue is solved, and new knowledge and skills are applied in different settings (Garrison et al., 2000).

The theory of CoI was chosen as a suitable framework for this study because the research focuses on ERT which is part of, although not synonymous with, traditional online learning. This research has as its focus students from a university in Kenya who, in response to instructions and guidance from their lecturers, formed an online community within which they were interacting to achieve certain learning goals. This process resonates with the $\mathrm{CoI}$ which assumes the formation of a learning community by a group of online students. Students' interactions within their online community in this study were guided by their lecturers. This teaching strategy aligns with the teaching presence component of the CoI. Students' application of higher-order thinking skills when solving educational problems was related to the cognitive presence in the $\mathrm{CoI}$. CoI is hinged within the basic principles of social constructivism in online settings. This is related to this study in the sense in which researchers examined how a sampled group of lecturers experienced ERT as examined through the lens of the CoI framework.

\section{Methodology}

The study used a qualitative case study design within an interpretive paradigm. A qualitative approach was chosen as the researchers wanted to collect rich textual data about the participants' experiences, views, and feelings about ERT within a CoI framework. For Creswell (2018) a qualitative approach is suitable for research that seeks to obtain textual data about a particular phenomenon. An interpretive paradigm was seen to be compatible with a qualitative approach, specifically in the depth of data collected and in the ontological experiences of lecturers, and the two (qualitative and interpretive) aspects enabled participants to express their views about the subject under investigation (Cohen, 
Manion \& Morrison, 2017). Lapan, Quartaroli, and Riemer (2012) see all qualitative research as having an interpretive perspective that focuses on uncovering participants' experiences. In this research, this approach and paradigm enabled participants to freely express their views about ERT, enabling us to understand in detail how these lecturers experienced ERT as examined through the lens of the $\mathrm{CoI}$ framework. The use of qualitative and interpretive methods enabled us to fill a gap that exists on lecturers' narrative experiences of teaching during the time of a global pandemic caused by COVID-19. A case study design was selected as it allowed the researchers to conduct an in-depth investigation of the phenomenon (Yin 2018). Cohen et al. (2017) describe case studies as very specific in terms of the participants, setting, and situation. This study focused on a specific group of participants (lecturers), and a particular setting (online classes), and with learning taking place within a crisis at a particular university (ERT).

\section{Participants}

Ten lecturers $(n=10)$ who were involved in ERT at a university in Kenya were purposively selected to participate in the study. This sample selection method was based on recruiting participants who indicated their consent to contributing to the development of ERT and learning in the broader university context. The sample was small as researchers wanted to interact both intensively and extensively with participants in seeking to understand their experiences of ERT as examined through the lens of the CoI framework. This is in line with Byman's (2016) proposition that purposive sampling is done with the "researcher's goal in mind" (p. 323).

\section{Instruments}

Data collection was done using virtual Zoom semi-structured interviews, following COVID-19 protocols for social distance to avoid the spread of the virus. The interview questions were reformulated from the Garrison et al. (2000) original survey to suit a qualitative approach. Each of the ten participants was interviewed for about 30 minutes. The researcher who conducted the interviews asked questions about lecturers' experiences of ERT. Based on the interviewees' responses, the researcher probed more questions in order to get rich textual data about each lecturer's experiences.

\section{Data Analysis and Procedures}

Data were analyzed using thematic analysis. A Computer-Assisted Qualitative Data Analysis Software (CAQDAS), Miner Lite, was used to analyze and code the data. This software helped in organizing, sorting, and coding the data. The search for codes in the data was guided by the CoI framework. We compared the single codes across the interviews in a data set (Hennik, Hutter \& Bailey, 2011). Then we categorized and conceptualized each code to the CoI presences concerning how it addressed the main research question on lecturers' experiences of ERT. Coded data were described using thick descriptions in terms of the depth, breadth, and context of lecturers' experiences of ERT to establish specific themes (Hennik, Hutter \& Bailey, 2011). The themes were grouped according to the CoI's three presences: teaching, cognitive, and social presences. Data was filtered through parts of each component. For instance, we used teaching presence as a theme with course design and organization, facilitating discourse and direct instruction as subthemes. This was repeated with the other three presences of the CoI.

The validity of the study was ensured by member checking to ensure the accuracy of the data and the themes that emerged from the data (Creswell \& Creswell, 2018); follow-up interviews were conducted with some respondents to validate the data. Validity was also ensured through a rich and thick description to convey the findings (Creswell \& Creswell, 2018:200). Ethical clearance was obtained from the Ethics Research Committee from the university in Kenya, and ethical considerations were adhered to at all stages in the study. The participants were informed that their participation was voluntary and confidential. Pseudonyms were used to ensure anonymity. Data were collected exclusively from participants who volunteered, signed, and submitted informed consent forms. 


\section{Results}

The findings are presented according to the components of the CoI. Major themes were classified into teaching, social, and cognitive presences. The results are presented below.

\section{Teaching Presence}

The results indicated that the lecturers established teaching presence by designing the course syllabus and schedule from existing curricula provided to them by Heads of Department. Some of the research participants reported that the syllabus and curriculum document from the University were already prescribed in terms of the course outcomes, goals, and purposes for the course. So, the lecturer's role was to interpret the curriculum, search for resources, and plan schedules and assessments as part of the course design. Certain lecturers (P1 and P7) indicated that:

The curriculum is designed in such a way that it describes the course which a lecturer is assigned to teach. And then it gives you the learning outcomes. So, as far as I am concerned, I am not only looking at the description of the course. I also look at the learning outcomes... (P1).

I actually teach in the course outline; I don't just take students through. So it's like for me my course outline becomes the course overview...because I can take three weeks to cover the course outline. But by the time I'm done, I have actually literally told the students about the quarter of what is expected in teaching the entire course (P7).

In terms of course design, one lecturer (P3) reported that it was challenging for him/her to redesign the existing course syllabus from traditional face-to-face to ERT due to the limited exposure to online teaching and learning:

The course syllabus ... was very difficult to understand even for me as a facilitator. This is partly because it was the first online learning that I was undertaking, and partly because I did not go through any training in preparation for online learning.

The limited experience of students in navigating around the LMS meant that certain lecturers were expected to orientate students to using the platform for online learning as confirmed by lecturer P3:

Most of them experienced difficulties in navigating through the Blackboard. I took the time to take them through the contents and how to access each section. This was very helpful as it saved them time in getting information and submitting their work.

Lecturers also experienced administrative challenges that were out of their control as a result of the university's bureaucratic processes. These challenges delayed the implementation of the course syllabus. Lecturer P1 reported on this issue:

The university processes, especially ... link between the admin and students, are not good. While I would like my course schedules to be ready on time, there are delays right from the beginning of the semester. This leads to delays in working out the schedules as planned. Nevertheless, my communication with the students is done on time. But, there is delayed student participation when it comes to the learning activities, either caused by the admin or by students themselves.

The results from the interviews show instances where individual lecturers (P6 and P2) applied direct instruction to assist students with understanding the course syllabus during ERT:

I took them through the syllabus step by step until they understood what they were expected to do. This facilitated their class participation (P6).

I make sure that my students have read and understood what we were trying to do ...So I try to ensure that I post a question in the form of a discussion question (DQ) or weekly compendium (WC) (P2).

Concerning direct instruction, lecturers explained course requirements to students during their first face-to-face virtual classes. Some lecturers referred to DQs and WCs.

Lecturer P7 described this process:

[DQs] is usually a question based on the course objectives; the students participate because they have to give one initial response for their DQ. In my case, it should be not less than 500 words for 
that question, then they should read at least five of their colleagues' responses and then critique them because the response is like a critique in about 250 words.

The same participant described WCs as

... a summary of what the student has learned in a given duration, normally in that week. And that learning is based on class discussions... (P7)

One lecturer (P1) referred to and described the learning process involved in the use of DQs as well as the role of direct instruction in facilitating this:

I make sure I have explained to students, especially during the first collaboration. I explain what is required of them, how to approach the required readings, what I expect with DQs and WCs, and the final paper. If a student is not clear when it comes to their reflections on DQs and WCs, I write back and ask them to clarify. But, I require them to go back and engage with the required reading for a proper reflection on the DQs and WCs. In the final paper, I require the students to engage with not less than five secondary sources. (P1)

Similarly, some lecturers (P8, P9, and P10) explained course requirements and focus as part of direct instruction:

In order to be sure that students are kept on track, I give direct instructions... first thing I do is to tell them that WC should be 500 words and the minimum should be also in five paragraphs (P8).

I come up with assignments/case studies that require them to reflect on relevant and contemporary issues (P9).

I tailor DQs and WCs to help them stay focused, relevant readings, and short video clips (P10).

The results indicated that students were told what to discuss in each paragraph and it was the lecturers' responsibility to facilitate these discussions. Facilitation is part of the teaching presence and it was done by lecturers, in different ways: the course requirements were explained to students during their first Face-to-face virtual classes held in Blackboard Collaborate.

Some of the facilitation approaches included group pedagogy in whole-class discussion and break-out groups on the zoom platform and Blackboard Collaborate while using a guest observer in the evaluation and feedback process. Lecturer P2 commented:

...I divide students into groups of either three or four, depending on the number of students that are in class. So, one of them is a therapist, the other one is the client and the other is the observer. And so, I observed with one guest observer, and we gave feedback to the one who was doing therapy in zoom breakout groups. And so I joined one group at a time while the other groups worked on it on their own. And so, after every 10 minutes, I shift to the other groups.

Furthermore, despite the initial stages of ERT concerning navigating the Learning Management System, one lecturer (P4) confirms that this initial struggle was subsequently followed by a strong social presence in which the students and lecturer motivated one another to learn how to use the LMS. Lecturer P4 comments:

Last semester both the students and I kept getting lost because we were learning how to navigate the LMS for the first time. So there was quite a bit of confusion that made all of us sometimes get alarmed and sometimes get amused. We just had to encourage each other and continue as we were learning to pick ourselves in this program. At the end of the semester, the students had achieved what was expected.

In summary, the teaching presence, therefore, was evident to some extent among particular lecturers in their approach to ERT. These individual lecturers reported doing this in the interviews on the design and organization of their courses, how they facilitated discourse and provided direct instruction. The results also confirm significant challenges for individual lecturers during ERT. These included the difficulty in [re]designing the existing traditional face-to-face curriculum to suit online learning as a result of inadequate training for ERT; limited experiences of students in navigating around the LMS, which significantly delayed the rapid transition to online learning and external factors beyond lecturers' control such as administrative challenges. There also appeared to be a social 
presence among the students and an individual lecturer which corroborates the interconnectedness between teaching and social presence in cultivating an online community during ERT.

\section{Cognitive Presence}

Lecturers were found to have established cognitive presence using triggering events by conceptualizing the course outcomes, content, and classroom discussions to provide the space for students to investigate critically and in-depth the solutions to problems and questions raised in their courses. Lecturers used a combination of synchronous and asynchronous teaching methods to enhance their students' learning experiences. Virtual face-to-face sessions were recorded, and students were able to download and review these recordings. The lecturers monitored the video download trends by students via the LMS analytics. The rates of participation and video downloads were indicators of triggering events that motivated students' cognitive capacities. Some lecturers helped develop their students' research and critical thinking skills to enable their exploration of various topics. This process was described by three lecturers (P2, P3, and P7):

Our students are good at gaining information. We are helping them to become critical thinkers. They are not good at synthesizing information. I help my students not just to be information sorters but, applying the knowledge and to become critical (P2).

I encourage the students not to copy and paste when they are answering the questions. I shared with them some useful websites where they can download books and showed them how to download updated Journals. Some of the students mentioned that they have found the information useful in solving some of the problems they encountered in their personal lives (P3).

I asked a question that is engaging for students to work out in DQs, WC, and class assignments. I also use current journal articles that relate to course outcomes. In addition, I use resource persons to speak in my classes as well. At times students interview the resource person about questions they have developed from their readings (P7).

To establish cognitive presence lecturers also used reflection to explore new knowledge. The explorative and reflective experiences by participants were based on broad reading around a case study or watching a video and reflecting on it.

Lecturer P7 described the process and the kinds of resources used in a reflective and explorative learning approach:

...I use videos such as Coach Carter, to teach team building and conflict management. The videos help students to reflect. I also use contemporary life examples; in this case, I draw out examples to them. The issue of presidents using the military to run some government agencies also was an example of a discussion we had in my class for students to explore... this was provocative and led them to think and analyze. I also use events in history to think about change in leadership approach. For instance, we use the Churchill example by creating possible scenarios for them to think exploratively.

Another lecturer (P5) used reflection to allow students to integrate theoretical and practical knowledge to improve their cognitive skills:

In most of my practical courses, students write reports as therapists. They reflect a lot. I ask students to stop and reflect. They are also able to write a treatment plan and present it in class and ask questions.

Concerning integration, Lecturer P4 explained that they managed to teach foundational theoretical knowledge to students during the synchronous sessions. They would then structure the asynchronous sessions to allow students to explore current situations in the real world that connect to what they have learned:

I engaged them in practical courses that they found useful because they were able to connect the theory of knowledge to the practical. I also tried in my classes to contextualize the content they were learning to connect to their experiences. This is useful but it does not cut across all courses. Unless students use cases, content to analyze the case in light of theory, learning can become rote (Lecturer P4). 
One lecturer (P3) also taught from the known to the unknown to integrate new knowledge acquired from research into his/her students' own experiences:

My objective every time I am teaching is to research and read more for any new information that I can share with students. I find this quite easy as it also broadens my knowledge of the subject matter. When students learn something in addition to what they know, they become more confident in answering any questions raised during the course activities

To ascertain cognitive presence in terms of resolution, certain lecturers indicated their confidence in their students' learning from the feedback they received, class presentations, assignments, and the general expression of students' satisfaction in the cases they engaged. Lecturers indicated that they were confident that their students were able to apply the knowledge they acquired in the course because they were able to do well in the assessments, articulate their acquired knowledge in classroom presentations, and showed a positive attitude towards the course. Three lecturers (P2, P4, and P7) confirmed this:

Because of the practical nature of the course, they are not only regurgitating what they have learned but, applying it to practical contexts in which they are assessed. How they apply the knowledge they have acquired is key to their learning. They have learned from one another, which is a way of learning with great value and broadening their repertoire skills. Online learning is a competency (P2).

From their confession through what they verbalize. Students' responses were quite good, especially on the application questions; the exam results were good but coursework boosted their grades (P4).

Yes, WC done every week for 12 weeks show how they will apply what they have learned to what they do in their work. They also discuss some implications of what they have learned in the course of personal leadership and allow them to go back to their journey. I also read their DQs and give them feedback. This has provided confidence that they have understood and can apply what they have learned in my course (P7).

In summary, despite some of the individual challenges identified in the initial stages of ERT, the results from the lecturers' interviews in this present study confirmed a significant cognitive presence among their students. More specifically, through students' exploration of information online, they were integrating a range of different kinds of information, synthesizing these, and resolving the problem. The stages of this process are integral parts of the cognitive presence.

\section{Social Presence}

The results from the interviews indicate there were instances of affective expression, group cohesion, and open communication. Open communication as an indicator of social presence was experienced by the lecturers in diverse ways, although their experiences of establishing open communication were often marred by students' anxiety and fear, especially at the beginning of ERT. Two lecturers (P1 and P2) reported on this:

There is still a level of "fear" - student to the lecturer. That is normal in our African context. I have not been able to check out how they feel when conversing with one another (P1).

...because the model was new last semester the students were anxious to figure out what was going on (P2).

One of the ways lecturers established social presence was their grouping of students. Lecturers identified reserved and poor-performing students and paired them with outspoken and high-performing students so they could help each other. Two lecturers (P1 and P4) reported on this:

When one student seems to be doing quite well with DQs or WCs, I direct weaker students to speak to that student and let him or her help them with a task. This allows the students to engage one another $(\mathrm{P} 1)$.

During the DQs, they connect. I had them in groups, where they presented their cases, and they gave each other feedback under my supervision, and then I wrapped up the feedback. So, students gave each other some feedback (P4). 
To facilitate open communication among students, some lecturers had created WhatsApp groups where students could speak and communicate further with one another. Lecturer P9 described the value of this for communication and collaborative learning:

I have a WhatsApp group for every class that I teach. We use the WhatsApp group because it is faster. And I can see what they are saying instantly because it shows it's a new message on my phone. I appointed somebody to start a new WhatsApp group. So, we can be able to keep communicating with each other.

Lecturers facilitated group cohesion among students in both synchronous and asynchronous classes. In asynchronous classes, students' discussions were facilitated through the LMS where lecturers crafted DQs to provoke students to think deeply, read, and post their findings from questions raised, and framed DQs in ways that encourage students to respond to each other's questions. In synchronous classes, students were grouped and encouraged to have open communication and group cohesion. When disagreements arose among students, the lecturer helped develop in students the social, interpersonal, and intrapersonal skills required for discourse, such as respect and patience for a diversity of views. Lecturer P7 supported this process designed to spark debates based on knowledge and research while respecting, and being open to, a diversity of views:

I keep house rules within my classroom such as respect for one another. So that the idea of disagreement does not arise and even if there is, students could engage with each other respectfully. I taught a course that draws students from different fields of study and so different students would have differing views. So their agreements were captured by indicating their limitations to their arguments. For instance one would say, I have answered, from my medical background or human resource perspective, another financial and public relations. Teaching graduate students provide space for the mature student who respects one another. My work becomes that of reconciling their views from a leadership perspective. There is a sense of trust therein. I have also seen others change their positions during class discussions.

In sum, according to the lecturers in this study, despite students' limited experiences with online learning, there was quite a strong social presence among the students during ERT. The results confirmed that lecturers encouraged students to participate in some interactive activities, use appropriate interpersonal and intrapersonal skills in affective expression and group tasks, and the social networking platform, WhatsApp for further open communication and group cohesion. It is also apparent from the results that synchronous and asynchronous teaching and learning were fundamental towards establishing this strong social presence among the students during ERT.

\section{Discussion}

Lecturers who participated in this study exposed their students to all three components of the CoI during ERT. The results confirmed the existence of cognitive presence when lecturers triggered students' learning by asking them questions or showing them videos to critique. This led students to explore course topics further by searching for more information online. This is consistent with the CoI learning process described by Swan et al., (2009) who contend that triggering and exploration occur in the cognitive presence when an online instructor poses a problem and asks students to search for relevant information that addresses the issue under investigation. Nyamboga and Ali (2020) describe such a situation where students at a university in Kenya were given opportunities to diagnose a problem and explore it further. This process forms part of the triggering and exploration which resonates with reports by the lecturers who participated in this current study where they were using multi-media resources to engage students in remote learning. The findings in this study indicated the rates of participation and video downloads were indicators of those triggering events that motivated students' cognitive educational experience.

It can be argued that, through their exploration of information online, these students integrated different information, synthesized it, and, through this process, resolved the problem. The integration and resolution these students applied are integral parts of the cognitive presence. Huho's (2020) 
research confirms cognitive presence among students at another Kenyan university when they managed to collaboratively explore the problem and to integrate and apply relevant information acquired online to come up with a resolution for developing ventilators and test kits. Garrison (2015) argues that cognitive presence will be attained when students collaboratively construct knowledge. ERT can thus be said to have opened up opportunities for self-directed learning and has become the new norm among many students across the globe (Aucejo et al., 2020; Hodges et al., 2020). With this learning model students are no longer spoon-fed information but search for it, make meaning from it, and use their higher-order critical thinking skills to assess this knowledge to solve problems (Swart, 2010).

The social presence was evident in this study when lecturers engaged students in discussions during synchronous classes (zoom breakout rooms and Blackboard Collaborate) and asynchronous classes (LMS). Engagement is the cornerstone of ERT and needs to be facilitated in a way that allows all students to take part (Whittle et al., 2020). Student engagement can be a challenge at the beginning of ERT, as some may not be used to the new learning style. This was reported by some lecturers in this study who noted students' anxiety due to fear of navigating through the LMS and adjusting to ERT. A United States study found some undergraduate students to struggle to adjust to ERT due to their being overwhelmed with their studies (Aucejo et al., 2020). The suddenness of ERT in response to a pandemic initially made it difficult for students throughout the world to transition from face-toface classes to online classes (Crawford et al., 2020). Some students have feared not being able to proceed to the next academic level (Bonk, Kefalaki, Rudolph, Diamantidaki, Munro, Karanicolas, Kontoleon, \& Pogner, 2020). There is a need to support students gripped with fear of remote learning and ensure there is no coercion and intimidation as this negatively affects open communication and discourages affective expression which are essential aspects of the social presence (Waghid, 2016).

The teaching presence was evident throughout this study as students' work was planned, designed, and facilitated by lecturers with haste in response to the COVID-19 crisis. Lecturers designed content for students to engage with and facilitated the discourse (Garrison \& Anderson, 2007). The lecturers also provided feedback to students on their learning, a process that is part of direct instruction and which falls under teacher presence as depicted by (Anderson et al., 2011). This study ascertains that exposing students to a full range of the CoI framework gives them opportunities to attain $21^{\text {st }}$-century skills which are essential graduate attributes. Hence, we agree with Waghid, Waghid, and Waghid (2019) who state that technologically informed pedagogic practices particularly in response to a pandemic or higher education crisis should be aimed at cultivating socially conscious and responsible students who can expand their technological capacities in the interest of establishing autonomous and deliberative communities of inquiry and transformative change.

\section{Conclusion}

The purpose of this study was to examine lecturers' experiences of ERT through the lens of the CoI framework. This study suggests that when a group of students is exposed to online teaching and learning framed within the constructs of the CoI, it helps cater to their diverse learning needs (in an online community). By implication, students would attain problem-solving and critical thinking skills, especially in situations where learning environments are isolated due to crisis and social distancing. The full application of the three components of the CoI, namely cognitive, social, and teaching presences in ERT enables students to engage with course content, the instructor, and their fellow students. This engagement is consequential since it enhances students' learning experiences as it allows them to explore course content using deep learner-centered methods. The practical implications of this study for higher education suggest that ERT has the potential of opening up opportunities for selfdirected learning, especially when constructed in constructivist ideas of learning which is essential in the 21 st century as it enables students to progress from being mere knowledge consumers to active knowledge producers. The study has further implications for course designers, lecturers, researchers, and students at residential universities and other educational institutions such as colleges and schools concerning curriculum re-design using a $\mathrm{CoI}$ to provide an adequate and effective online learning 
experience and develop insight into students' level of involvement in online learning. There are also certain limitations of this study. First, the sample size of ten lecturers was significantly small at a university in Kenya. Other studies can also explore students' perspectives concerning ERT since the current research was limited to lecturers' experiences. Second, this present study was limited to a single tertiary institution. Similar studies in both developing and developed contexts in universities at a larger scale can be initiated as a means of determining best practice pedagogical approaches concerning ERT in response to a higher education crisis. 


\section{REFERENCES}

Affouneh, S., Salha, S., \& Khlaif, Z. N. (2020). Designing quality E-Learning environments for emergency remote teaching in Coronavirus crisis. Interdisciplinary Journal of Virtual Learning in Medical Sciences, 11(2), 1-3.

Agormedah, E. K., Henaku, E. A., Ayite, D. M. K., \& Ansahd, E. A. (2020). Online learning in higher education during COVID-19 pandemic: A case of Ghana. Journal of Educational Technology \& Online Learning, 3(3), $183-210$.

Alawamleh, M., Al-Twait, L. M., \& Al-Saht, G. R. (2020). The effect of online learning on communication between instructors and students during Covid-19 pandemic. Asian Education and Development Studies. Retrieved from https://www.emerald.com/insight/content/doi/10.1108/AEDS-06-2020-0131/full/pdf?title=the-effect-of-onlinelearning-on-communication-between-instructors-and-students-during-covid-19-pandemic

Almuraqab, N. A. S. (2020). Shall universities at the UAE continue distance learning after the COVID-19 pandemic? Revealing students' perspective. International Journal of Advanced Research in Engineering and Technology, 11(5), 226-233. PMID:32714122

Anderson, T. (2011). Teaching in an online learning context. In T. Anderson (Ed.), The theory and practice of online learning (pp. 343-366). Athabasca University Press.

Aucejo, E. M., French, J., Araya, M. P. U., \& Zafar, B. (2020). The impact of COVID-19 on student experiences and expectations: Evidence from a survey. Journal of Public Economics, 191, 1-15. doi:10.1016/j. jpubeco.2020.104271 PMID:32873994

Boling, E. C., Hough, M., Krinsky, H., Saleem, H., \& Stevens, M. (2012). Cutting the distance in distance education: Perspectives on what promotes positive, online learning experiences. The Internet and Higher Education, 15(2), 118-126. doi:10.1016/j.iheduc.2011.11.006

Bonk, R. J., Kefalaki, M., Rudolph, J., Diamantidaki, F., Munro, C. R., Karanicolas, S., Kontoleon, P., \& Pogner, K. (2020). Pedagogy in the time of pandemic: From localisations to glocalisation. Journal of Education, Innovation, and Communication, 17-64. Retrieved from https://discovery.ucl.ac.uk/id/eprint/10101902/1/1_SP_ JEICOM_JUNE_2020_Bonk-et-al_Pedagogy-in-the-Time-of-Pandemic.pdf

Bozkurt, A. et al.. (2020). A global outlook to the interruption of education due to COVID-19 pandemic: Navigating in a time of uncertainty and crisis. Asian Journal of Distance Education, 15(1), 1-126.

Bozkurt, A., \& Sharma, R. C. (2020). Emergency remote teaching in a time of global crisis due to Coronavirus pandemic. Asian Journal of Distance Education, 15(1), 1-4.

Bryman, A. (2016). Social research methods (4th ed.). Oxford University Press.

Crawford, J., Butler-Henderson, K., Rudolph, J., Malkawi, B., Glowatz, M., Burton, R., Magni, P. A., \& Lam, S. (2020). COVID-19: 20 countries' higher education intra-period digital pedagogy responses. Journal of Applied Learning \& Teaching, 13(1), 9-28.

Garrison, D. R. (2015). Thinking collaboratively: learning in a community of inquiry. Routledge., doi:10.4324/9781315740751

Gillett-Swan, J. (2017). The Challenges of online learning: Supporting and engaging the isolated learner. Journal of Learning Design, 10(1), 20-30. doi:10.5204/jld.v9i3.293

Hennink, M., Hutter, I., \& Bailey, A. (2011). Qualitative research methods. SAGE.

Hodges, C. B., Moore, S., Lockee, B. B., Trust, T., \& Bond, M. (2020). The difference between emergency remote teaching and online learning. Educase Review. Retrieved from https://medicine.hofstra.edu/pdf/faculty/ facdev/facdev-article.pdf

Huho, J. M. (2020). The two sides of Covid-19 in Kenya: Getting a closer look. International Journal of Scientific and Research Publications, 10(8), 478-484. doi:10.29322/IJSRP.10.08.2020.p10459

Ministry of Education. (2020). Kenya basic education COVID-19 emergency response plan, May 2020. Republic of Kenya: Ministry of Education. Retrieved from https://www.education.go.ke/images/Kenya_basic_Education_ COVID-19_Emergency_Response_Plan-compressed.pdf 
Mkonto, N. (2018). Monitoring Student (Dis)engagement: Retention officers' experiences at the Cape Peninsula University of Technology. Journal of Student Affairs in Africa, 6(1), 65-76. doi:10.24085/jsaa.v6i1.3066

Motala, S., \& Menon, K. (2020). In search of the 'new normal': Reflections on teaching and learning during Covid-19 in a South African university. Southern African Review of Education, 26(1), 80-99.

Ngwacho, A. G. (2020). COVID-19 pandemic impact on Kenyan education sector: Learner challenges and mitigations. Journal of Research Innovation and Implication in Education, 4(2), 128-139.

Nyamboga, T. O., \& Ali, H. A. (2020). Adoption of digital literacy strategy on academic progress of private university education in Kenya: A survey of Umma University, Garissa Campus. Asian Journal of Economics. Business and Accounting, 19(2), 24-39.

Ontong, K., \& Waghid, Z. (2020). Towards cultivating a critical pedagogy of splace: a response to teaching practices in Higher Education amidst COVID-19. In Re-thinking the Humanities Curriculum in the Time of COVID-19. Durban: CSSALL Publishers.

Ouma, R. L. (2020). "Switching to SIDE Mode"- COVID-19 and the adaptation of computer mediated communication learning in Kenya. Research Association for Interdisciplinary Studies Conference Proceedings, 8(2020), 17-18. Retrieved from http://rais.education/wp-content/uploads/2020/08/012LR.pdf

Paschal, M. J., \& Mkulu, D. G. (2020). Online Classes during COVID-19 pandemic in higher learning institutions in Africa. Global Research in Higher Education, 3(3), 1-21. doi:10.22158/grhe.v3n3p1

Rahiem, M. D. H. (2020). The emergency remote learning experience of university students in Indonesia amidst the COVID-19 crisis. International Journal of Learning, Teaching and Educational Research, 19(6), 1-26.

Stenbom, S., Jansson, M., \& Hulkko, A. (2016). Revising the community of inquiry framework for the analysis of one-to-one online learning relationships. International Review in Open and Distributed Learning., 17(3), 36-53.

Swan, K., Garrison, D., \& Richardson, J. (2009). A constructivist approach to online learning: The community of inquiry framework. In Information Technology and Constructivism in Higher Education: Progressive Learning Frameworks (pp. 43-57). Academic Press.

Sykes, P., \& Gachago, D. (2018). Creating 'safe-ish' learning spaces - attempts to practice an ethics of care. South African Journal of Higher Education, 32(6), 83-98. doi:10.20853/32-6-2654

Tarus, J. K., \& Gichoya, D. (2015). E-learning in Kenyan universities: Preconditions for successful implementation. The Electronic Journal on Information Systems in Developing Countries, 66(4), 1-14. doi:10.1002/j.1681-4835.2015.tb00474.x

UNESCO. (2020). COVID-19 and higher education: Today and tomorrow: Impact analysis, policy responses and recommendations. Retrieved 13 October 2020 from: http://www.iesalc.unesco.org/en/wp-content/ uploads/2020/04/COVID-19-EN-090420-2.pdf

Waghid, Y., Waghid, Z., \& Waghid, F. (2019). The Fourth Industrial Revolution Reconsidered: On Advancing Cosmopolitan Education. South African Journal of Higher Education, 33(6), 1-9. doi:10.20853/33-6-3777

Waghid, Z. (2016). Using film and online group blogs to cultivate a community of inquiry: A case at a university of technology in South Africa. Progressio: South African Journal for Open and Distance Learning, 38(2), 106-131.

Whittle, C., Tiwari, S., Yan, S., \& Williams, J. (2020). Emergency remote teaching environment: A conceptual framework for responsive online teaching in crises. Information and Learning Sciences, 121(5/6), 311-319. doi:10.1108/ILS-04-2020-0099

Woolfolk, A. (2014). Educational psychology (12th ed.). Pearson.

World Bank. (2020). Guidance note on education systems' response to COVID19. Retrieved from http:// documents1.worldbank.org/curated/en/450881585235950757/Guidance-Note-on-Education-Systems-Responseto-COVID19.pdf

ZhangW. N.WangY. X.YangL. L.WangC. Y. (2020). Suspending classes without stopping learning: China's education emergency management policy in the COVID-19 outbreak. Journal of Risk and Financial Management, $13(55), 2-6$. 
Jane Adhiambo Chiroma (Ph.D., Stellenbosch University, South Africa) serves as a Senior lecturer faculty in the Department of Leadership at Pan Africa Christian University, Nairobi, Kenya, and runs a consultancy in E-learning, research, and leadership development. Dr. Chiroma engages in interdisciplinary research in Democratic Education, Higher Education Policy, Curriculum studies, Public theology, Educational Technology, and pedagogy. In addition to this is a budding interest in environmental education.

Lawrence Meda works as an Assistant Professor in the College of Education at Zayed University in Dubai. His research interests are in Curriculum Studies, Educational Technology, Inclusive Education, and Teacher Education.

Zayd Waghid is a Senior lecturer in the Faculty of Education at the Cape Peninsula University of Technology in South Africa. He is the co-author of three books, Educational Technology and Pedagogic Encounters: Democratic Education in Potentiality in 2016 (Sense Publishers), Rupturing African Philosophy of Teaching and Learning: Ubuntu Justice and Education in 2018 (Palgrave-MacMillan) and Cosmopolitan Education and Inclusion: The Self and Others in Deliberation in 2020 (Palgrave-MacMillan). His current research interests are in the field of social justice education and educational technology within the context of teacher education. 